\title{
Farklı atık materyallerin Matthiola incana 'Iron Rose' yetiştiriciliğine etkisi
}

\section{The effects of different waste materials on growing Matthiola incana 'Iron Rose'}

\author{
Gülbin ÇETINKALE DEMIRKAN ${ }^{1}$, Hülya AKAT ${ }^{2}$, Bülent YAĞMUR ${ }^{3}$ \\ ${ }^{1}$ Niğgde Ömer Halisdemir Üniversitesi, Mimarlık Fakültesi, Peyzaj Mimarlığı Bölümü, 51240, Niğde \\ ${ }^{2}$ Muğla Sttkı Koçman Üniversitesi, Ortaca Meslek Yüksekokulu, Peyzaj ve Süs Bitkileri Programı, 48600, Ortaca/Muğla \\ ${ }^{3}$ Ege Üniversitesi, Ziraat Fakültesi, Toprak Bilimi ve Bitki Besleme Bölümü, 35040, Bornova/İzmir \\ Sorumlu yazar (Corresponding author): G. Çetinkale Demirkan, e-posta (e-mail): gulcetinkale@ ohu.edu.tr
}

\section{MAKALE BILGISİ}

Alınıs tarihi 04 Nisan 2017

Düzeltilme tarihi 03 Kasım 2017

Kabul tarihi 07 Kasım 2017

\section{Anahtar Kelimeler:}

Arıtma çamuru

Balık atı̆̆ 1

Kesme çiçek

Kömür cürufu

Organik atık

\begin{abstract}
Öz
Örtüaltı koşullarda gerçekleștirilen çalıșmada, kontrol ortamı olarak toprak kullanılmıș ve bu ortama 1:1 oranında arıtma çamuru, balık atığı ile kömür cürufu materyalleri ilave edilerek 4 farklı yetiştirme ortamı oluşturulmuştur. Matthiola incana 'Iron Rose' çeşidinde atık materyallerin yetiştiriciliğge etkisinin belirlenmesi amacıyla, sürgündeki yaprak sayısı, sürgün uzunluğu, sürgün kalınlığı, kök uzunluğu, kök yaş ve kuru ağırlığı, çiçek sapı üzerindeki yaprak sayısı, çiçek sapı uzunluğu, çiçek sapı kalınlığı ve başak uzunluğu kriterleri incelenmiştir. Verilerin istatistiksel analizi sonucunda, sürgündeki yaprak sayısı, sürgün kalınlığı, kök uzunluğu, çiçek sapı uzunluğu ve çiçek sapı kalınlığı kriterlerinde $\mathrm{p}<0.01$, başak uzunluğunda ise $p<0.05$ önem düzeyinde farklılıklar olduğu tespit edilmiștir. Elde edilen sonuçlar doğrultusunda, toprağa arıtma çamuru ve balık atığı karıştırılarak elde edilen ortamlarda, Matthiola incana 'Iron Rose' çeşidinin yetiştiriciliğinde kullanılabilirliğinin mümkün olduğu tespit edilmiştir.
\end{abstract}

\section{ARTICLE INFO}

Received 04 April 2017

Received in revised form 03 November 2017 Accepted 07 November 2017

\section{Keywords:}

Sewage sludge

Fish waste

Cut flower

Coal slag

Organic waste

\begin{abstract}
In this study carried out greenhouse condition, soil was used as the control media and 4 different growing media were formed by adding to soil 1:1 treatment sludge, fish waste and coal slag materials. Leaf number on shoot, shoot length, shoot diameter, root length, root wet and dry weight, leaf number on flower pedicle, flower pedicle length, flower pedicle thickness and spike length criteria were carried out for the effects of these waste materials on growing of Matthiola incana 'Iron Rose' variety. According to statistical analyzes of the data, leaf number on shoot, shoot diameter, root length, flower pedicle length and flower pedicle thickness criteria were significant at $p<0.01$, but spike length was significant at $p<0.05$. The results showed that the sewage sludge and fish waste medias are suitable for growing of Matthiola incana 'Iron Rose' variety.
\end{abstract}

\section{Giriş}

Tarımsal faaliyetlerin devamlılı̆̆ için toprak ve su gibi olmazsa olmaz doğal kaynakların korunarak sürdürülebilirliğinin sağlanması oldukça önemlidir. Bu doğal kaynakların bileşiminde meydana gelen değişiklikler tarım ürünlerinin kalite ve verimlerini de olumsuz yönde etkileyebilmektedir (Karaer ve Gürlük 2003). Buna ilaveten ekonomik kalkınma ile birlikte ülkelerin çevreye verdikleri zararlar daha da artmaktadır (Stern 1998). Bunun bir sonucu olarak doğal kaynakların çevre üzerinde hızla artan baskısı ciddi olumsuz etkiler meydana getirmektedir (Karaer ve Gürlük 2003). Nüfus artışına paralel olarak katı atık miktarının da yoğunlaşmasıyla çevre kirliliği ve uzaklaştırma problemleri günümüzde acil çözüm bulunması gereken konular arasında yerini almaktadır. Bu sorunların ortadan kaldırılması amacıyla ekonomik, kabul edilebilir ve çevre dostu teknolojiler geliştirilerek atıkların geri dönüşümünün sağlanması gerekliliğ ortaya çıkmıştır (Topal ve Topal 2013). Yeniden kullanılabilen organik içeriği yüksek atıkların geri dönüşümü sağlandığında kaynakların korunmasının yanı sıra çevre üzerine binen yük azaltılarak düzenli depo alanlarına giden atık miktarının da minimize edilmesi sağlanacaktır. Bu doğrultuda yapılan çoğu çalışma, organik atık olarak nitelendirilen materyallerin toprağa direkt veya belirli oranlarda karıştırılarak kullanımlarının, bitkilerin organik madde ve bitki besin elementi ihtiyacını karşılayabileceğini; özellikle son yıllarda hızla gelişen ve büyük bir ekonomik paya sahip bir sektör olan süs bitkisi yetiştiriciliğinde, çimlendirme ve yetiştirme ortamı olarak da kullanılabilirliğinin mümkün olabildiği ortaya konulmuştur (Çıtak ve ark. 2006; Şimşek Erşahin 2007; Bozdoğan ve ark. 2009; Çetinkale ve Söğüt 2010; López-Mosquera ve ark. 2011; 
Akat ve ark. 2013; Çetinkale Demirkan ve ark. 2014; Öten ve ark. 2016; Pekşen ve Yamaç 2016). Akat ve ark. (2015) çalışmalarında Limonium sinuatum türünde arıtma çamuru dozlarından $(\% 25,50,75,100)$ en iyi sonucu toprağa $\% 75$ oranında karıştırdıkları arıtma çamurundan alsalar da, uzun vadede arıtma çamuru kullanımlarında, bitkinin besin elementlerinden daha fazla yararlanması ve herhangi bir toksik etki oluşmaması ya da yaratılmaması amacıyla \%50 doz uygulamasının kullanımını tavsiye etmişlerdir. Ayrıca, organik içerikli atıkların bu şekilde kullanımının, önemli bir gider olan gübreleme maliyetlerinin de düşürülmesine katkı sağlayarak, atıkların bertarafınıda ekolojik ve ekonomik bir çözüm niteliği taşıdığ 1 da söylenebilmektedir (Smith 1985; Teuber ve ark. 2005; Illera-Vives ve ark. 2015). Ancak içerisinde birçok kirletici etmeni de barındıran bazı katı atıkların süs bitkisi yetiştiriciliğinde dikkatli bir şekilde kullanılması ve yönetmeliklere uyulması gerektiği göz ardı edilmemesi gereken konular arasında yer almaktadır (Kranert ve ark. 2008; Çetinkale Demirkan ve ark. 2013; Akat ve ark. 2015).

Yürütülen bu çalışma ile ekonomik değeri yüksek, kokusu ile etkili, kesme çiçek yetiştiriciliğinde popüler bir tür olarak tercih edilen Matthiola incana 'Iron Rose' çeşidinde, bertarafi ve depolanması konusunda çevre açısından ciddi sorunlar yaratan arıtma çamuru, balık atığı ve kömür cürufunun, bitki gelişimi ve çiçek kalitesi üzerine etkileri araştırılarak yetiştiriciliğe etkisinin ne yönde olduğunun belirlenmesi amaçlanmıştır.

\section{Materyal ve Yöntem}

Çalışma Muğla Sıtkı Koçman Üniversitesi Ortaca Meslek Yüksekokuluna ait örtüaltı koşullarda saksı denemesi şeklinde 2015-2016 yılları arasında gerçekleştirilmiştir. Araştırmada stabilize arıtma çamuru, balık atığı ve kömür cürufu atıkları ayrı ayrı ve toprağa eşit miktarda ilave edilmiş, hiçbir uygulamanın yapılmadığ 1 toprak materyali ise kontrol grubunu oluşturacak şekilde, 4 farklı ortam, deneme konuları olarak ele alınmıştır (Çizelge 1).

Çizelge 1. Yetiştirme ortamları.

Table 1. Growth media.

\begin{tabular}{ll}
\hline Uygulamalar & \\
\hline Toprak (Kontrol) & A1 \\
Toprak : Arıtma Çamuru (1:1) & A2 \\
Toprak : Balık Atığı $(1: 1)$ & A3 \\
Toprak : Kömür Cürufu (1:1) & A4 \\
\hline
\end{tabular}

Denemede kullanılan biyolojik ve termal yöntem ile stabilize edilmiş atık su arıtma çamuru; Gökova Akyaka Atık $\mathrm{Su}$ Arıtma Tesisi'nden temin edilerek bazı analizler yaptırılmıştır. Elde edilen sonuçlar Çevre ve Orman Bakanlığı tarafindan 03.08.2010 tarihli 27661 sayılı Resmi Gazete (2010) de yayınlanmış olan 'Evsel ve Kentsel Arıtma Çamurlarının Toprakta Kullanılmasına Dair Yönetmelik'te belirlenen toprakta kullanılabilecek stabilize arıtma çamurunda müsaade edilen maksimum ağır metal içerikleri açısından incelenip uygunluğu tespit edildikten sonra incelenip toprağa karıştırılarak araştırmada kullanılmıştır.

Kömür cürufu; 'Mopak-Dalaman Selüloz-Kağıt-Karton Entegre Tesisleri'nde kömür kazanına atılan kömürlerin küle dönüşmesinden sonra islak filtreden geçerek depo alanında kurutulması sonucu elde edilerek araştırmada kullanılmıştır. Toprağa karıştırılan bir diğer materyal ise, Bağcı Beyobası/Köyceğiz Alabalık Üretim Tesisindeki 100 küçük yetiştirme havuzunun ardından 30 büyük yetiştirme havuzuna geçiş yapan sediment ve Oncorhynchus mykiss (Gökkuşağ 1 Alabalığı) türüne ait balık dışkılarının, en son çamur havuzunda birikmesi sonucu elde edilmiştir. Bu balık atığ materyali havuzdan kepçe yardımıyla sıyrılıp alınarak güneşte iyice kurutulduktan sonra denemede kullanılmıştır.

Araştırmada kullanılan toprak materyali, arıtma çamuru, balık atığı ve kömür cürufunun bazı fiziksel ve kimyasal özelliklerini belirlemek amacıyla çeşitli analizler ve ölçümler yapılmıştır. Denemede kullanılan yetiştirme materyallerine ait analiz sonuçları Çizelge 2 ve 3 'de verilmiştir.

Çizelge 2. Stabilize arıtma çamuruna ait bazı fiziksel ve kimyasal analiz sonuçları.

Table 2. Some physical and chemical analysis results of stabilized sewage sludge.

\begin{tabular}{lccc}
\hline Yapılan Analizler & Birim & $\begin{array}{c}\text { Arıtma } \\
\text { Çamuru }\end{array}$ & $\begin{array}{c}\text { Yönetmelik Sınır } \\
\text { Değerleri* }\end{array}$ \\
\hline $\mathrm{pH}(1: 5)$ & & 6.59 & - \\
EC & $\left(\mathrm{mS} \mathrm{cm}^{-1}\right)$ & 5.08 & - \\
Toplam Azot & $(\%)$ & 1.93 & - \\
Toplam Fosfor & $(\%)$ & 0.20 & - \\
Toplam Potasyum & $(\%)$ & 0.09 & - \\
Toplam Kalsiyum & $(\%)$ & 6.75 & - \\
Toplam Magnezyum & $(\%)$ & 6.55 & - \\
Toplam Sodyum & $(\%)$ & 0.04 & - \\
Toplam Demir & $(\%)$ & 1.42 & - \\
Toplam Mangan & $(\mathrm{ppm})$ & 405.38 & - \\
Toplam Kobalt & $(\mathrm{ppm})$ & 18.79 & - \\
Toplam Bakır & $(\mathrm{ppm})$ & 7.84 & 1000 \\
Toplam Çinko & $(\mathrm{ppm})$ & 546.50 & 2500 \\
Toplam Nikel & $(\mathrm{ppm})$ & 371.29 & 300 \\
Toplam Kadmiyum & $(\mathrm{ppm})$ & 2.48 & 10 \\
Toplam Krom & $(\mathrm{ppm})$ & 189.25 & 1000 \\
Toplam Kurşun & $(\mathrm{ppm})$ & 31.26 & 750 \\
\hline
\end{tabular}

*03.08.2010 tarihli 27661 Sayılı Resmi Gazetedeki evsel ve kentsel arıtma çamurlarının toprakta kullanılmasına dair yönetmelik.

Çizelge 3. Toprak, balık atı̆̆ı ve kömür cürufuna ait bazı fiziksel ve kimyasal analiz sonuçları.

Table3. Some physical and chemical analysis results of soil, fish waste and coal slag.

\begin{tabular}{lcccc}
\hline $\begin{array}{c}\text { Yapılan } \\
\text { Analizler }\end{array}$ & Birim & Toprak & Balık Atığı & $\begin{array}{c}\text { Kömür } \\
\text { Cürufu }\end{array}$ \\
\hline $\mathrm{pH}(1: 5)$ & & 7.32 & 7.08 & 11.37 \\
$\mathrm{EC}$ & $\left(\mathrm{mS} \mathrm{cm}^{-1}\right)$ & 0.96 & 1.813 & 2.41 \\
Toplam N & $(\%)$ & 0.07 & 1.372 & 0.28 \\
Toplam P & $(\%)$ & 0.27 & 0.32 & 0.54 \\
Toplam K & $(\%)$ & 0.23 & 0.53 & 0.24 \\
Toplam Ca & $(\%)$ & 6.25 & 10.38 & 7.88 \\
Toplam Mg & $(\%)$ & 9.32 & 6.33 & 1.02 \\
Toplam Na & $(\%)$ & 0.03 & 0.12 & 0.24 \\
Toplam Fe & $(\%)$ & 3.39 & 1.11 & 2.33 \\
Toplam Cu & $(\mathrm{ppm})$ & 4.03 & 27.21 & 20.30 \\
Toplam Zn & $(\mathrm{ppm})$ & 181.75 & 309.88 & 336.25 \\
Toplam Mn & $(\mathrm{ppm})$ & 600.13 & 338.38 & 265.63 \\
Toplam $\mathrm{Ni}$ & $(\mathrm{ppm})$ & 94.88 & 39.70 & 96.08 \\
Toplam Co & $(\mathrm{ppm})$ & 42.25 & 18.10 & 11.36 \\
Toplam Cd & $(\mathrm{ppm})$ & 2.14 & 2.63 & 2.38 \\
Toplam Cr & $(\mathrm{ppm})$ & 59.25 & 13.75 & 52.13 \\
Toplam Pb & $(\mathrm{ppm})$ & 11.71 & 6.86 & 41.84 \\
\hline
\end{tabular}


Çizelge 2 ve 3'de verilen ortamlardan toprak, arıtma çamuru, balık atığı ve kömür cürufunda tepkime $(\mathrm{pH})$, saf su ile doyurulmuş (1:5) örneklerde cam elektrotlu pH-metre kullanılarak (Jackson 1967), EC değeri, saf su ile doygun örneğin EC-metrede okunmasiyla (Soil Survey Staff 1951), toplam-N, modifiye kjeldahl yöntemi belirlenmiştir (Bremmer 1965). Toprak, arıtma çamuru ve kömür cürufunda makro ve kimi iz element ile ağır metal içeriklerinin belirlemesi amacıyla kral suyu $\left(3: 1 \mathrm{HCl}+\mathrm{HNO}_{3}\right)$ ile yaş yakma, balık atığı için nitrik per klorik asit karışımı $\left(4: 1 \mathrm{HNO}_{3}+\mathrm{HClO}_{4}\right)$ ile yaş yakma yöntemi uygulanarak ekstratlar elde edilmiştir. Elde edilen bu ekstraktlarda toplam-P fosfor Vanada-Molibdo fosforik sarı renk yöntemine göre kolorimetrik olarak (Loot ve ark. 1956), toplam-K, toplam-Ca, toplam-Na alev fotometresinde okunarak (Kacar 1995), toplam-Mg ile kimi ağır metal ve iz element içerikleri $(\mathrm{Fe}, \mathrm{Cu}, \mathrm{Zn}, \mathrm{Mn}, \mathrm{Cd}, \mathrm{Cr}, \mathrm{Co}, \mathrm{Pb}, \mathrm{Ni}$ ) atomik absorbsiyon spektrofotometre cihazında (AAS) okunarak (Kick ve ark. 1980; Slawin 1955) belirlenmiştir.

Bitkisel materyal olarak ise Matthiola incana 'Iron Rose' çeşidi kullanılmıştır. 09.09.2015 tarihinde örtüaltı yapıda multipotlara tohum ekimi yapılmış ve 13.10.2015 tarihinde torf:cüruf:toprak (1:1:1) karışımının bulunduğu alıştırma ortamına şaşırtılmışlardır. 07.11.2015 tarihinde 10 litrelik saksılardaki deneme konularını oluşturan esas yetiştirme ortamlarına dikilmişlerdir.

Dikimden üç hafta sonra besleme amaciyla Hoagland çözeltisi 15 günde bir olacak şekilde uygulanmıştır (Hoagland ve Arnon 1950). Hasat işlemleri haftada bir, deneme boyunca 4 kez olacak şekilde, başak üzerindeki kandillerin 3-5 tanesi açıldığında, toprak seviyesinin hemen üzerinden kesilerek sürgündeki yaprak sayısı (adet bitki ${ }^{-1}$ ), sürgün uzunluğu $(\mathrm{cm})$, sürgün kalınlığı (mm) ölçümleri yapılmıştır (Akat ve ark. 2013). Hasat edilen tüm çiçeklerde, çiçek sapı üzerindeki yaprak sayısı $\left(\right.$ adet bitki $\left.{ }^{-1}\right)$, çiçek sap1 uzunluğu $(\mathrm{cm})$, çiçek sap1 kalınlığ $(\mathrm{mm})$ ve başak uzunluğu $(\mathrm{cm})$ belirlenmiștir. 11.05.2015 tarihinde hasatların tamamlanıp sonlandırılmasıyla kök uzunluğu $(\mathrm{cm})$, kök yaş ağırlığı $(\mathrm{g})$ ve etüvde $65^{\circ} \mathrm{C} 48$ saat bekletilen örneklerin kök kuru ağırlığ $(\mathrm{g})$ tespit edilmiştir (Kacar 1972). Araştırma ortamlarından alınan bitki köklerinde bazı bitki besin elementi analizleri yapılmıştır. Kuru ağırlıkları belirlenen bitki örnekleri mikro değirmende öğütülerek analize hazır hale getirilmiştir (Kacar 1972). Kurutulup öğütülerek analize hazırlanan bitki örneklerinde toplam azot modifiye makro Kjeldahl yöntemi ile (Kacar 1984); toplam P, K, Ca, Na, $\mathrm{Mg}, \mathrm{Fe}, \mathrm{Cu}, \mathrm{Zn}, \mathrm{Mn}$ miktarları Kacar (1972)'a göre analize hazır hale getirilmiş örneklerinde yaş yakma yöntemi uygulanarak elde edilen ekstraktlarda; toplam fosfor VanadaMolibdo fosforik sarı renk yöntemine göre Eppendorf kolorimetresinde okunarak (Loot ve ark. 1956), toplam K, Na, ve Ca miktarları Eppendorf flame fotometresinde; toplam $\mathrm{Mg}$,
$\mathrm{Fe}, \mathrm{Cu}, \mathrm{Zn}, \mathrm{Mn}$ miktarları ise Perkin Elmer 2380 atomik absorbsiyon spektrofotometre cihazında okunarak saptand (Kacar ve İnal 2008) Yürütülen araştırmadan elde edilen veriler, TARİST istatistik paket programı ile değerlendirilerek tesadüf parselleri deneme desenine göre (3 tekerrürlü olarak her bir uygulama konusunda 30 bitki yer alacak şekilde toplam 120 bitki ile) varyans analizine tabi tutulmuş ve önemlilik gösteren ortalamalar arası farklılıklar LSD yöntemiyle karşılaştırılmıştır.

\section{Bulgular ve Tartışma}

Araştırmada ele alınan kriterler açısından atık materyallerin bitki gelişimi üzerine etkileri Çizelge 4'de verilmiştir.

Atık materyallerin toprakla karıştırılarak kullanıldı $\breve{g}_{1}$ ortamlardan sürgündeki yaprak sayısı, sürgün kalınlığı ve kök uzunluğu $\mathrm{p}<0.01$ önem düzeyinde etkilenmiştir. Sürgündeki yaprak sayısı 41.00 adet bitki $^{-1}$, sürgün kalınlığ $5.10 \mathrm{~mm}$ ve kök uzunluğunun $21.67 \mathrm{~cm}$ ile en yüksek değerlerine toprak ile arıtma çamuru karışımında $\left(\mathrm{A}_{2}\right)$ ulaşılmıştır. $\mathrm{Bu}$ değerleri sürgündeki yaprak sayısı ve sürgün kalınlığı kriterlerinde arıtma çamuru ile istatistiksel olarak aynı grupta bulunan toprak ile balık atığı karışımından $\left(\mathrm{A}_{3}\right)$ elde edilen değerler takip etmektedir. En düşük değerler ise sürgündeki yaprak sayısında

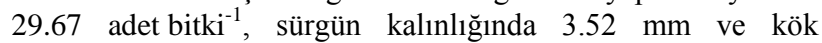
uzunluğunda $15.22 \mathrm{~cm}$ ile toprak ile kömür cürufu karışımından $\left(\mathrm{A}_{4}\right)$ elde edilmiştir. İstatistiksel analiz sonucunda önem ifade etmeyen sürgün uzunluğu, kök yaş ağırlığ kriterlerinde de en yüksek değerlere toprak ile karıştırılan arıtma çamuru ortamlarında $\left(\mathrm{A}_{2}\right)$ ulaşılmıştır. Ostos ve ark. (2008); Pistacia lentiscus, Dede ve ark. (2009); Primula vulgaris türündeki çalışmalarında arıtma çamuru ilavesinin bitki gelişimini olumlu etkilediğini ortaya koymuşlardır. Patel ve Patra (2014), Tagetes mitula türünde en iyi gelişimin toprak:arıtma çamuru (50:50) karışımından elde edildiğini belirtmişlerdir. Çetinkale Demirkan ve ark. (2014), Clarkia amoena türünde arıtma çamurunu farklı dozlarda (\% 0, 25, 50, 75) toprak ile karıştırarak yaptıkları çalışmalarında sürgün uzunluğu, çiçek sayısı ve kök uzunluğuna ait değerlerin artan dozlar ile artış gösterdiğini ve $\% 50$ ve $\% 75$ doz uygulamalarının farklı parametreler için ilk sıralarda yer aldığını bildirmişlerdir. Yine benzer bir çalışmada, Limonium sinuatum türünde arıtma çamurunun farklı dozlarda $(\% 0,25$, 50,75 ve 100) toprakla karıştırarak kullanımında, en uzun kökler \% 50 arıtma çamuru uygulamasından elde edilmiştir (Akat ve ark. 2015). İncelenen çalışmalar, arıtma çamuru uygulamalarının bitki büyüme performansı açısından yürütülen bu çalışma ile benzer özellikler göstermesi bulgularımızı destekleyen bir sonuç olarak karşımıza çıkmaktadır.

Atık materyallerin çiçek gelişimi üzerine etkisine ait değerler Çizelge 5'de verilmektedir.

Çizelge 4. Atık materyallerin Matthiola incana 'Iron Rose' çeşidinin vegetatif gelişimi üzerine etkisi.

Table 4. The effect of waste materials on the vegetative development of Matthiola incana 'Iron Rose'.

\begin{tabular}{ccccccc}
\hline & $\begin{array}{c}\text { Sürgündeki Yaprak } \\
\left.\text { Sayısı (adet bitki }{ }^{-1}\right)\end{array}$ & $\begin{array}{c}\text { Sürgün Uzunluğu } \\
(\mathbf{c m})\end{array}$ & $\begin{array}{c}\text { Sürgün Kalınlı̆̆ı } \\
(\mathbf{m m})\end{array}$ & $\begin{array}{c}\text { Kök Uzunluğu } \\
(\mathbf{c m})\end{array}$ & $\begin{array}{c}\text { Kök Yaş Ağırlı̆̆ } \\
(\mathbf{g})\end{array}$ & $\begin{array}{c}\text { Kök Kuru Ağırlı̆ı } \\
(\mathbf{g})\end{array}$ \\
\hline $\mathrm{A}_{1}$ & $33.67 \mathrm{~b}$ & 24.92 & $3.67 \mathrm{~b}$ & $17.22 \mathrm{bc}$ & 7.91 & 1.30 \\
$\mathrm{~A}_{2}$ & $41.00 \mathrm{a}$ & 28.11 & $5.10 \mathrm{a}$ & $21.67 \mathrm{a}$ & 11.80 & 1.91 \\
$\mathrm{~A}_{3}$ & $38.33 \mathrm{a}$ & 26.82 & $4.71 \mathrm{a}$ & $18.44 \mathrm{~b}$ & 11.49 & 1.65 \\
$\mathrm{~A}_{4}$ & $29.67 \mathrm{c}$ & 25.25 & $3.52 \mathrm{~b}$ & $15.22 \mathrm{c}$ & 7.44 & 1.24 \\
$\mathbf{L S D}$ & $\mathbf{3 . 6 5}^{* *}$ & $\mathbf{O ̈ d}$ & $\mathbf{0 . 6 3}^{* *}$ & $\mathbf{3 . 1 2} * *$ & Öd & Öd \\
\hline
\end{tabular}

A 
Çiçek sap1 uzunluğu ve kalınlığ1 istatistiki olarak $p<0.01$ düzeyinde, başak uzunluğu ise istatistiki açıdan $\mathrm{p}<0.05$ önem düzeyinde etkili bulunmuştur. Çiçek sapı uzunluğu $57.55 \mathrm{~cm}$, çiçek sap1 kalınlığ1 $9.99 \mathrm{~mm}$ ve başak uzunluğu $15.89 \mathrm{~cm}$ ile diğer kriterler de olduğu gibi en yüksek değerlere toprak ile arıtma çamuru karışımında $\left(\mathrm{A}_{2}\right)$ ulaşmıştır. $\mathrm{Bu}$ değerleri istatistiksel olarak aynı grupta bulunan toprak ile balık atığı karışımından $\left(\mathrm{A}_{3}\right)$ elde edilen değerlerin takip ettiğ belirlenmiştir. En düşük değerler ise çiçek sapı uzunluğunda $49.89 \mathrm{~cm}$, çiçek sapı kalınlığında $6.85 \mathrm{~mm}$ ve başak uzunluğunda $12.33 \mathrm{~cm}$ ile toprak ile kömür cürufu karışımından $\left(\mathrm{A}_{4}\right)$ elde edilmiştir. Ünal ve ark. (2011), Freesia spp. (Arpa Zambağı) türüne farklı dozlarda $\left(0,30,60,90\right.$ ve $\left.180 \mathrm{t} \mathrm{ha}^{-1}\right)$ arıtma çamuru uygulayarak başak ve çiçek sapı uzunluğunda artan dozların toprağa göre olumlu etkiler yaptığını tespit etmişlerdir. Benzer şekilde Xue ve Huang (2013) arıtma çamuru kompostunun Paeonia suffruticosa (Şakayık) bitkisinin, çiçek çapını arttırdığını belirlemişlerdir. Akat ve ark. (2015), Limonium sinuatum türünde farklı dozlarda $(\% 0,25,50,75$, 100) arıtma çamuru uyguladıkları çalışmalarında çiçek sayısı, çiçek sapı uzunluğu ve çiçek sapı kalınlığına ait değerlerin \% 50 ve üzerindeki doz uygulamalarının istatistiksel olarak aynı grupta bulunarak en yüksek değerlerin elde edildiğini bildirmişlerdir. Değerlendirilen literatürler ile yürütülen bu çalışmada bitki gelişimi ve çiçek kalitesi açısından sonuçların toprağa ilave arıtma çamurunun kullanıldığı ortamlarda en iyi sonucun elde edilmesi yönünden paralellik göstermiştir.

Denemenin sonunda alınan bitki kök örneklerinden elde edilen bitki besin elementi analizlerine ait değerler Çizelge 6'da verilmektedir.

Çizelge 6'daki değerler incelendiğinde, kökteki N, P, Ca ve $\mathrm{Na}$ içerikleri, kullanılan atık materyaller arasında $\mathrm{p}<0.01$ önem düzeyinde etkili bulunurken; $\mathrm{K}$ içeriği $\mathrm{p}<0.05$ önem düzeyinde etkili bulunmuştur. Araştırma materyali toprak örneği ve balık atığ1 nötr, arıtma çamuru hafif asit, kömür cürufunun kuvvetli alkali reaksiyona sahip, toprakta tuzluluk yönünden herhangi bir sorun bulunmazken arıtma çamuru, balık atığı ve kömür cürufunun tuz içeriği yüksektir. Araştırmada kullanılan dört materyalde de toplam $\mathrm{N}, \mathrm{P}, \mathrm{K}$ orta düzeyde, toplam $\mathrm{Ca}$ ve $\mathrm{Mg}$ yeterli düzeydedir. Araştırma materyallerinin (toprak, arıtma çamuru, balık atığı, kömür cürufu) kimi iz element ve ağır metal (toplam $\mathrm{Fe}, \mathrm{Cu}, \mathrm{Zn}, \mathrm{Mn}, \mathrm{Cd}, \mathrm{Co}, \mathrm{Cr}, \mathrm{Pb}$ ve $\mathrm{Ni}$ ) içerikleri, gerek evsel ve kentsel arıtma çamurlarının toprakta kullanılmasına dair yönetmelikte verilen sınır değerler gerekse Scheffer ve Schachtschabel (1989) ve Kloke (1980)'in verdiği sınır değerleri ile karşılaştırıldığında herhangi bir kirlilik unsurunun bulunmadığ 1 , toprak (Ni kritik değer 50 ppm) ve arıtma çamurunda (kritik değer 300 ppm) nikel içeriğinin biraz yüksek olduğu saptanmıştır.

Araştırma sonucunda yetiştirme ortamlarından deneme sonunda alınan bitki kök örneklerinin makro ve mikro besin element sonuçları incelendiğinde toplam $\mathrm{N}, \mathrm{P}, \mathrm{K}, \mathrm{Ca}, \mathrm{Mg}, \mathrm{Na}$, içeriklerinin sırasıyla \% $1.37-1.96 ; \quad 0.20-0.39 ; \quad 1.75-2.68$; $0.43-0.87$; $0.29-0.36$; $0.04-0.07$; toplam $\mathrm{Fe}, \mathrm{Cu}, \mathrm{Zn}$ ve $\mathrm{Mn}$ içeriklerinin ise 414-2048; 11.43-19.40; 44.48-59.67; 27.65-101.15 ppm arasında değiştiği saptanmıştır. Bitkilerin asıl beslenme organlarının bitki köklerinin olması, kök beslenmesinin bitkinin gelişimine ve verimine direkt etkide bulunması sebebiyle köklerdeki besin maddesi miktarları son derece önemlidir. Kökün büyümesi, morfolojisi ve toprak profilinde kök sisteminin dağılımı üzerine bitki besin elementlerinin etkisi önemlidir. Özellikle azotun etkisi yüksek düzeyde olup bunu fosfor izler. Yeterli düzeyde bitki besin elementine sahip ortamlarda kök büyümesi yeteri düzeyde besin maddesi içermeyen ortamlara göre daha fazladır. Bu durum gübreleme çalışmalarıyla da kanıtlanmıştır (Kacar ve Katkat 2006).

Çizelge 5. Atık materyallerin Matthiola incana 'Iron Rose' çiçek gelişimi üzerine etkisi.

Table5. The effect of waste materials on the Matthiola incana 'Iron Rose' flower development.

\begin{tabular}{ccccc}
\hline & $\begin{array}{c}\text { Çiçek Sapındaki Yaprak } \\
\left.\text { Sayısı (adet bitki }{ }^{-1}\right)\end{array}$ & $\begin{array}{c}\text { Çiçek Sapı Uzunluğu } \\
(\mathbf{c m})\end{array}$ & $\begin{array}{c}\text { Çiçek Sapı Kalınlığı } \\
(\mathbf{m m})\end{array}$ & $\begin{array}{c}\text { Başak Uzunluğu } \\
(\mathbf{c m})\end{array}$ \\
\hline $\mathrm{A}_{1}$ & 48.33 & $53.33 \mathrm{~b}$ & $7.97 \mathrm{bc}$ & $13.55 \mathrm{bc}$ \\
$\mathrm{A}_{2}$ & 51.00 & $57.55 \mathrm{a}$ & $9.99 \mathrm{a}$ & $15.89 \mathrm{a}$ \\
$\mathrm{A}_{3}$ & 51.33 & $56.22 \mathrm{ab}$ & $8.68 \mathrm{ab}$ & $15.22 \mathrm{ab}$ \\
$\mathrm{A}_{4}$ & 45.33 & $49.89 \mathrm{c}$ & $6.85 \mathrm{c}$ & $12.33 \mathrm{c}$ \\
LSD & Öd & $\mathbf{2 . 9 8 * *}$ & $\mathbf{1 . 5 2}^{* *}$ & $\mathbf{2 . 1 8}^{*}$ \\
\hline
\end{tabular}

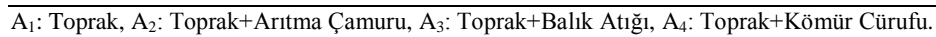

Çizelge 6. Atık materyallerin Matthiola incana 'Iron Rose' köklerindeki bazı bitki besin elementi analiz sonuçları.

Table 6. The results of some plant nutrients analyses in the Matthiola incana 'Iron Rose' root at waste materials application.

\begin{tabular}{|c|c|c|c|c|c|c|c|c|c|c|}
\hline & & & & $\mathrm{T}$ & $\mathrm{O}$ & $M$ & & & & \\
\hline & $\begin{array}{c}N \\
(\%)\end{array}$ & $\begin{array}{c}\mathrm{P} \\
(\%)\end{array}$ & $\begin{array}{c}\mathbf{K} \\
(\%)\end{array}$ & $\begin{array}{c}\mathbf{C a} \\
(\%)\end{array}$ & $\begin{array}{l}\mathrm{Mg} \\
(\%)\end{array}$ & $\begin{array}{c}\mathrm{Na} \\
(\%)\end{array}$ & $\begin{array}{c}\mathbf{F e} \\
(\mathbf{p p m})\end{array}$ & $\begin{array}{c}\mathbf{C u} \\
(\mathbf{p p m})\end{array}$ & $\begin{array}{c}\mathbf{Z n} \\
(\mathbf{p p m})\end{array}$ & $\begin{array}{c}\text { Mn } \\
(\mathbf{p p m})\end{array}$ \\
\hline $\mathrm{A}_{1}$ & $1.540 \mathrm{~b}$ & $0.203 b$ & $1.750 \mathrm{~b}$ & $0.873 a$ & 0.330 & $0.070 \mathrm{a}$ & 2048.50 & 19.400 & 59.670 & 101.150 \\
\hline $\mathrm{A}_{2}$ & $1.370 \mathrm{~b}$ & $0.343 \mathrm{a}$ & $2.053 \mathrm{ab}$ & $0.430 \mathrm{~b}$ & 0.290 & $0.043 b$ & 414.00 & 11.433 & 48.973 & 27.650 \\
\hline $\mathrm{A}_{3}$ & $1.960 \mathrm{a}$ & $0.393 a$ & $2.330 \mathrm{ab}$ & $0.453 b$ & 0.350 & $0.060 \mathrm{a}$ & 445.25 & 17.700 & 56.983 & 34.850 \\
\hline $\mathrm{A}_{4}$ & $1.483 \mathrm{~b}$ & $0.373 \mathrm{a}$ & $2.683 \mathrm{a}$ & $0.480 \mathrm{~b}$ & 0.360 & $0.043 b$ & 1003.60 & 12.647 & 44.483 & 30.850 \\
\hline LSD & $0.212 * *$ & $0.054 * *$ & $0.634 *$ & $0.147 * *$ & Öd & $0.015^{* * *}$ & Öd & Öd & Öd & Öd \\
\hline
\end{tabular}

$\mathrm{A}_{1}$ : Toprak, $\mathrm{A}_{2}$ : Toprak+Arıtma Çamuru, $\mathrm{A}_{3}$ : Toprak+Balık Atığı, $\mathrm{A}_{4}$ : Toprak+Kömür Cürufu. 


\section{Sonuç}

Tarım sektöründe başarının odak noktası üreticileri daha fazla verim elde etme çabasına yöneltmiştir. Günümüzde kontrollü koşullar altında hemen her mevsimde bitkisel üretim yapılabilmesi, tarımda kullanılan girdi ve üretilen tarımsal atık miktarının yanı sıra sanayi kaynaklı atık materyaller de artış göstermektedir. Son zamanlarda çevresel kirliliğin önlenebilmesi ve doğal kaynakların sürdürülebilirliğinin sağlanması amacıyla kullanılabilir atıkların tarım sektöründe, özellikle gıda ürünü olarak tüketilmemeleri sebebiyle süs bitkileri alanında yeniden kullanılmasının sağlanması çevre üzerindeki baskının azaltılmasına destek sağlayacaktır. Bu doğrultuda Matthiola incana 'Iron Rose' çeşidinin yetiştiriciliğinde farklı atık materyallerinin kullanılmasında; atık su arıtma çamuru ve balık atığının toprağa karıştırılması bitki gelişimi ile ilgili incelenen sürgündeki yaprak sayısı, sürgün kalınlığı, kök uzunluğu ile çiçek kalitesine ait çiçek sap1 kalınlığı, çiçek sapı ve başak uzunluğu parametrelerini önemli düzeyde olumlu etkilemiştir. En yüksek değerler atık su arıtma çamuru ve bunu takiben balık atığının toprağa karıştırılmasından alınırken, en düşük değerler ise kömür cürufu ilavesinde tespit edilerek, bu değerlerin ilk iki karışımda olumlu sonuçlar vermesinin organik yapılarından kaynaklandığı düşünülmektedir. Bu doğrultuda arıtma çamuru ve balık atığının tuz içeriğinin de bitki türünün yetiştiriciliğine bir engel teşkil etmemesi durumunda bitki gelişimine olumlu katkılar sağlayacağından tarımda kullanılmaları rahatlıkla önerilmektedir. Elde edilen verilerin 1şı̆̆ında toprağa ilave edilen atık su arıtma çamuru ile balık atığının Matthiola incana 'Iron Rose' çeşidinin kesme çiçek olarak değerlendirilmesinin dışında peyzaj alanlarında kullanılması bu atıkların bertarafının daha geniş alanlarda da sağlanabilmesine olanak tanıyacaktır. Ancak özellikle atık su arıtma çamuru uygulamalarının yönetmeliklerce izin verilen sınır değerlerin altında ağır metal içeriğine sahip olmaları ve karıştırıldıkları topraklarda gerekli ölçümler ile denetimlerin yapılması koşuluyla kullanımlarına olanak verilmelidir. Toprakta müsaade edilen sınır değerlerin aşılması durumunda ise atık su arıtma çamuru uygulamasının sonlandırılması ile çevreye zarar vermeyecek şekilde daha bilinçli kullanımları anlamında etkili olunacağı kanaatine varılmıştır.

\section{Kaynaklar}

Akat H, Demirkan ÇG, Yokaş İ (2013) Atık çamurun 'Matthiola incana' yetiştiriciliğinde bitki gelişimi ve kalite üzerine etkisi. 5 . Ulusal Katı Atık Yönetimi Kongresi Kocaeli, s. 508-520.

Akat H, Çetinkale Demirkan G, Akat Ö, Yağmur Ö, Yokaş İ (2015) Arıtma çamuru uygulamalarını Limonium sinuatum 'Compindi White' çeşidinde bitki gelişimi, verim ve çiçek kalitesi üzerine etkileri. Ege Üniversitesi Ziraat Fakültesi Dergisi 52(1): 107-114.

Bozdoğan E, Çetinkale G, Söğüt Z (2009) Atık su arıtma çamurlarının yeniden kullanımları. Ulusal Katı Atık Yönetimi Kongresi Eskişehir, s. 334-342.

Bremmer JM (1965) Total Nitrogen. Edit. C.Black. Methods of Soil Analysis. Part 2. Amer. Soc. Of Agr. Inc., Publisher, Madison, Wisconsin, USA.

Çetinkale G, Söğüt Z (2010) Cynodon dactylon (L.) Pers. çim alanlarında kentsel su arıtım sistem çamurlarından yararlanabilme olanakları. Ç.Ü. Fen Bil. Ens. Fen ve Mühendislik Bilim. Dergisi Cilt 23(3): 11-21.

Çetinkale Demirkan G, Akat H, Yokaş İ (2013) Atık çamurun kapak malzemesi olarak kullanımının bazı çim türlerine etkisi. V. Süs Bitkileri Kongresi Cilt 1, Yalova, s. 301-308.
Çetinkale Demirkan G, Akat H, Yokaş İ (2014) Atık su arıtma çamurunun Clarkia amoena (Yer Açelyası) türünde bitki gelişimi ve çiçeklenme üzerine etkisi. Uludağ Üniversitesi Ziraat Fakültesi Dergisi 28(2): 49-57.

Çıtak S, Sönmez S, Öktüren F (2006) Bitkisel kökenli atıkların tarımda kullanılabilme olanakları. Derim, Batı Akdeniz Tarımsal Araştırma Enstitüsü Dergisi. 23(1): 40-53.

Dede ÖH, Özdemir S, Dede G (2009) Findık zürufu ve arıtma çamurlarının tek yıllık süs bitkisi yetiştiriciliğinde kullanılması. II. Ulusal Arıtma Çamurları Sempozyumu, İzmir, s. 275-280.

Hoagland DR, Arnon DI (1950) Growing Plants Without Soil. Cal. Agric, Exp. Sta. Ciro, 347: 1-32.

Illera-Vives M, Labandeira SS, Brito LM, Lopez-Fabal A, LopezMosquera ME (2015) Evaluation of compost from seaweed and fish waste as a fertilizer for horticultural use. ScientiaHorticulturae 186: 101-107.

Jackson ML (1967) Soil Chemical Analysis. Prentice HallInc., Engle Wood Cliff, New Jersey.

Kacar B (1972) Bitki ve toprağın kimyasal analizleri. A.Ü.Z.F. Yayın 453.

Kacar B (1984) Bitki Besleme. Ankara Üniversitesi Ziraat Fakültesi Yayınları: 899, Ders Kitabı: 250. 2. Bask1.

Kacar B (1995) Bitki ve Toprağın Kimyasal Analizleri III. A.Ü.Z. F. Eğitim Araştırma ve Geliştirme Vakfi Yayınları, No: 3, s: 255.

Kacar B, Katkat V (2006) Bitki Besleme. Nobel Yayın Dağıtım. No: 849 Fen ve Biyoloji Dizisi: 29, Ankara.

Kacar B, İnal A (2008) Bitki analizleri. Nobel Yayın Dağıtım, Ankara.

Karaer F, Gürlük S (2003) Gelişmekte olan ülkelerde tarım-çevreekonomi etkileşimi. Doğuş Üniversitesi Dergisi 4(2): 197-206.

Kick H, Burger H, Jommer K (1980) Gesamtgehalte an Pb, Zn, Sn, As, $\mathrm{Cd}, \mathrm{Hg}, \mathrm{Cu}, \mathrm{Ni}, \mathrm{Cr}$ und $\mathrm{Co}$ in Land wirtschaftlichund Gortnerisch Genutzen Boden Nordrhein-Westfalen. Land wirtschaftliche Forschung 33, 1, 12-22.

Kloke A (1980) Orientierungstaden für tolerierbare gesamtghalte einiger elemente in kulturboden. (Richwerte 80). Biologische Bundesantaitfor Land und Forstwirstchaft, Berlin.

Kranert M, Hafner G, Berkner I, Erdin E (2008) Compost from sewage sludge - a product with quality assurance system. Water Practice\&Technology IWA Publishing 2008doi:10.2166/wpt.2008.008.

Loot WL, Nerry JP, Gallo JR, Medcaff JC (1956) Leaf Analysis Technique in Coffee Research, IBEC Researc Ins.II. 9., pp: 21-24 New York.

López-Mosquera ME, Fernandez-Lema E, Villares R, Corral R, Alonso $\mathrm{B}$, Lanco C (2011) Composting fish waste and sea weed to produce a fertilizer for use in organic agriculture. ProcediaEnv. Sci. 9: 113-117.

Ostos JC, López-Garrido R, Murillo JM, López R (2008) Substitution of peat for municipal solid waste and sewage sludge based composts in nursery growing media: effects on growth and nutrition of the native shrub Pistacia lentiscus L. Biosource Technology 99: 1793-1800.

Öten M, Temirkaynak M, Tokgöz H, Güven D, Gübbük H (2016) Bazı tarımsal atık uygulamalarının açıkta muz yetiştiriciliğinde kullanım olanakları. Derim Batı Akdeniz Araştırma Enstitüsü Dergisi 33(1): 1-13.

Patel A, Patra DD (2014) Influence of heavy metal rich tannery sludge on soil enzymes vis-à-vis growth of Tagetes mitula, an essential oil bearing crop. Chemosphere 112: 323-332.

Pekşen A, Yamaç M (2016) Atık mantar kompostu/substratının kullanım alanları-1: özellikleri ve önemi. Mantar Dergisi 7(1): 49-60. 
Resmi Gazete (2010) 27661 say1l 03.08.2010 tarihli 'Evsel ve Kentsel Arıtma Çamurlarının Toprakta Kullanılmasına Dair Yönetmelik.

Scheffer F, Schachtschabel P (1989) Lehrbuck der Bodenkunde. 12 neu Bearb. Aufl. Unter Mitarb. Von W.R., Fischer Ferdinand Enke Verlag Stuuugart.

Slawin W (1955) Atomic Absorbtion Spectroscopy. Interscience Publishers, New York-London-Sydney.

Smith JH (1985) Fertilizing agricultural and with rainbow trout manure for growing silage corn. Soil Science Society of America Journal 49(1): 131-134.

Soil Survey Staff (1951) Soil Survey Manuel. U.S. Department Agriculture Handbook N0.18, U.S. Goverment Printing Office, Washington.

Stern D (1998) Progress on the environmental Kuznetscurve. Environmental Development Economics 3. ss.175-178.
Simșek Erșahin Y (2007) Vermikompost ürünlerinin eldesi ve tarımsal üretimde kullanım alternatifleri. GOÜ. Ziraat Fakültesi Dergisi 24 (2): 99-107.

Teuber N, Alfaro MA, Salazar FJ, Bustos C (2005) Sea salmon sludge as fertilizer: effects on a volcanic soil and annual ryegrass yield and quality. Soil Use and Management 21: 432-434.

Topal Arslan EI, Topal M (2013) Kompost standartları üzerine bir derleme. Nevşehir Bilim ve Teknoloji Dergisi 2 (2): 85-108.

Ünal M, Karaca A, Camcı ÇS, Çelik A (2011) İçme suyu tesisi arıtma çamurunun arpa zambağı (Freesia spp.) bitki gelişimi ve bazı toprak özellikleri üzerine etkileri. Selçuk Tarım ve Gıda Bilimleri Dergisi 25 (2): 46-56.

Xue D, Huang X (2013) The impact of sewage sludge compost on tree peony growth and soil microbiological, and biochemical properties. Chemosphere 93: 583-589. 